\title{
Erratum: Aberrant Long-Range Temporal Correlations in Depression Are Attenuated after Psychological Treatment
}

\author{
Frontiers Production Office* \\ Frontiers Media SA, Lausanne, Switzerland
}

Keywords: depression, EEG, long-range temporal correlations, theta, mindfulness, stress-reduction

\section{An erratum on}

Aberrant Long-Range Temporal Correlations in Depression Are Attenuated after Psychological Treatment

by Gärtner, M., Irrmischer, M., Winnebeck, E., Fissler, M., Huntenburg, J. M., Schroeter, T. A., et al. (2017) Front. Hum. Neurosci. 11:340. doi: 10.3389/fnhum.2017.00340

The publisher failed to include the following affiliation for Vadim V. Nikulin:

Department of Neurology, Max Planck Institute for Human Cognitive and Brain Sciences, Leipzig, Germany

The original article has been updated as follows:

OPEN ACCESS

Approved by:

Frontiers in Human Neuroscience Editorial Office,

Frontiers Media SA, Switzerland

*Correspondence:

Frontiers Production Office production.office@frontiersin.org

Received: 06 October 2017 Accepted: 06 October 2017 Published: 12 October 2017

Citation

Frontiers Production Office (2017)

Erratum: Aberrant Long-Range Temporal Correlations in Depression Are Attenuated after Psychological Treatment.

Front. Hum. Neurosci. 11:509. doi: 10.3389/fnhum.2017.00509
Matti Gärtner ${ }^{1}$, Mona Irrmischer ${ }^{2}$, Emilia Winnebeck ${ }^{3}$, Maria Fissler ${ }^{3}$, Julia M. Huntenburg ${ }^{3}$, Titus A. Schroeter ${ }^{3}$, Malek Bajbouj ${ }^{1}$, Klaus Linkenkaer-Hansen ${ }^{2}$, Vadim V. Nikulin ${ }^{\mathbf{4 , 5}, \mathbf{6 *} \dagger}$ and Thorsten Barnhofer $^{3 \dagger}$

${ }^{1}$ Department of Psychiatry and Psychotherapy, Charité-Universitätsmedizin Berlin, Campus Benjamin Franklin, Berlin, Germany

${ }^{2}$ Department of Integrative Neurophysiology, Center for Neurogenomics and Cognitive Research, Vrije Universiteit Amsterdam, Amsterdam, Netherlands

${ }^{3}$ Dahlem Center for Neuroimaging of Emotions, Freie Universität Berlin, Berlin, Germany

${ }^{4}$ Department of Neurology, Max Planck Institute for Human Cognitive and Brain Sciences, Leipzig, Germany

${ }^{5}$ Department of Neurology and Clinical Neurophysiology, Charité-Universitätsmedizin Berlin, Campus Benjamin Franklin, Berlin, Germany

${ }^{6}$ Center for Cognition and Decision Making, National Research University Higher School of Economics, Moscow, Russia

Copyright $(2017$ Frontiers Production Office. This is an open-access article distributed under the terms of the Creative Commons Attribution License (CC BY). The use, distribution or reproduction in other forums is permitted, provided the original author(s) or licensor are credited and that the original publication in this journal is cited, in accordance with accepted academic practice. No use, distribution or reproduction is permitted which does not comply with these terms. 